\title{
Analyzing the barriers affecting the effective utilization of quality tools and techniques using integrated ISM approach
}

\author{
Vivek Sharma ${ }^{a^{*}}$, Sandeep Grover ${ }^{\mathrm{b}}$ and S. K Sharma ${ }^{\mathrm{c}}$
}

${ }^{a}$ Research Scholar, Department of Mechanical Engineering, YMCA University of Science \& Technology, Faridabad, Haryana, India ${ }^{b}$ Professor, Department of Mechanical Engineering, YMCA University of Science \& Technology, Faridabad, Haryana, India ${ }^{c}$ Professor (retd), Department of Mechanical Engineering, NIT Kurukshetra, Kurukshetra, Haryana, India

CH R O N I C L E A B S T R A C T

Article history:

Received: February 1, 2017

Received in revised format: July 6, 2017

Accepted: July 6, 2017

Available online:

August 7, 2017

Keywords:

Integrated interpretive structural

modeling (IISM)

MICMAC

QT\&T barriers

\begin{abstract}
The aim of this study is to recognize and scrutinize the barriers affecting the utilization of quality tools and techniques (QT\&T) in manufacturing organizations. For this purpose, twelve barriers affecting the execution of QT\&T in manufacturing organizations have been identified from literature analysis and experts' opinion (academicians and industrial). Questionnaire-based survey has been utilized for the validation of identified barriers. Afterwards, an integrated model of QT\&T has been developed by using interpretive structural Modelling (ISM) and Matriced Impacts Croisés Multiplication Appliquée á un Classement (MICMAC) approach. This research gives an apparent depiction to identify and handle the barriers by computing the effectiveness of each barrier. Barriers like accessibility of time and space, inability to change organizational culture and inadequate coordination and teamwork are found to be the key barriers for utilization of QT\&T in manufacturing organization. The developed model will help the manufacturing organizations effectively utilize QT\&T.
\end{abstract}

\section{Introduction}

Manufacturing organizations largely enable speedy, smooth and economical manufacture of products. During the last two decades, superior manufacturing recital has led to sustainable improvement in quality tools and techniques (QT\&T) to support the manufacturer aspects. Evidently, manufacturers have been trying to improve their performance together by aiming manufacturing systems and products for immense development (Baumgartner \& Zielowski, 2007; Kara et al., 2007; Gehin et al., 2008; Ingwersen \& Stevenson, 2012). Hence manufacturing organizations must improve the quality of their products for achieving spirited advantage, and shifted to the path of growth and excellence. Many researchers and practitioners have focused on effective utilization of QT\&T to accomplish the demands of manufacturing organizations. For this purpose, numerous identified QT\&T and systematic methodologies have been adopted by manufacturing organizations for enhancing their performance. A variety of factors are involved in today's manufacturing arena for improved quality and productivity. These

* Corresponding author.

E-mail address: sharmvivme@gmail.com (V. Sharma) 
factors perceive different actions on various manufacturing organizations. Kara et al., (2005); Kaebernick and Kara (2006) suggested that five major factors namely environmental aims; environmental performance; early stage product development implementation; implementation from top to down and bottom to up; and simplicity are responsible for successful implementation of product development concepts and methodologies. Each phase of conversion i.e. raw materials into finished products requires a scrupulous production planning that contributes to the requisite production target and optimize the resources utilization (Muhammad \& JengFeng, 2014). In order to achieve and apprehend the required task, manufacturing organizations must identify certain barriers that affect the effective utilization of QT\&T. The manufacturing organizations prompt to find barriers which help them achieve effectiveness. Researchers put their efforts to recognize and classify these barriers in order to develop the suitable strategy for tackling the barriers which influence the effective utilization of QT\&T. Consequently various barriers have been acknowledged in text by the different authors but no work is available to allocate the effectiveness of QT\&T in an organization. This could be done by proposing an integrated interpretive structural modeling (ISM) and MICMAC analysis which bridges the gap between different organizations. Furthermore, assessment and interactions among the various barriers of QT\&T will clarify an integrated ISM-MICMAC model to evaluate effectiveness in a manufacturing organization. In view of this, twelve barriers have been recognized from extensive literature review, opinions of academic and industrial experts. These identified barriers are analyzed by integrated ISM- MICMAC in order to build up a categorized structural model. Finally effectiveness of each barrier has been computed after subtracting from driver power to dependence power. The main objectives of this paper are:

- To identify and rank the barriers affecting the utilization of QT\&T in manufacturing organizations;

- To find out the interaction between identified barriers affecting the utilization of QT\&T using integrated ISM-MICMAC approach;

- To organize barriers into different categories; and

- To confer the managerial implications of the current work and propose directions for future work.

\section{Literature background}

Barriers can be considered as obstructions posed to avert the successful utilization of QT\&T in manufacturing organizations. These barriers diminish the efficiency of quickness, adaptability, intellect shape and knowledge-driven capabilities of manufacturing organizations. Some experts from academic $\&$ industries were asked to recognize the key barriers affecting QT\&T in manufacturing organizations. The details of these barriers are as follows:

1. Employee's resistance to change $\left(\mathbf{B}_{1}\right)$ : Manufacturing organizations intended to counter out the pressure for gradually more globalized and competitive environment for rapidly change conditions that demands quick decision-making and innovation activity (Abuelmaatti \& Rezgui, 2008). Employees working in the manufacturing organization must educate for the successful implementation of the program (Khurana, 2009).

2. Motivational technique and recipient organizations $\left(\mathbf{B}_{2}\right)$ : Employees who work within a defined frame take less attention towards motivational techniques concerning the utilization of QT\&T in manufacturing organizations. Raj and Attri (2011) emphasized that motivation allows change in the behavior of employees towards work from pessimistic to optimistic approach.

3. Lack of continuous communication $\left(\mathbf{B}_{3}\right)$ : Lack of continuous communication is critical to assist the knowledge flow in manufacturing organizations. It affects lack of coordination, cooperation and team work which may obstruct the effective utilization of QT\&T. Improved communication prevents misunderstandings and trim down the costs of quality by avoiding mistakes (Cohen \& Brand, 1993; Talib et al., 2011).

4. Inability to change organizational culture $\left(\mathbf{B}_{4}\right)$ : Organizational framework is associated to the right business environment and conditions. The arrangement of the venture divides its labor 
into distinct tasks and then achieves coordination (Abuelmaatti and Rezgui, 2008). Top management must be able modify organizational culture for civilizing performance and competence.

5. Inadequate coordination and teamwork $\left(B_{5}\right)$ : Inadequate coordination and teamwork is the most important barrier existing in the Indian manufacturing organizations. It becomes extremely tough to execute any improvement program when the employees are not succeed to work jointly as a team and determines the implementation of nature and extent of quality program (Sureshchandar et al., 2001).

6. Dilemma about organization policies $\left(\mathbf{B}_{6}\right)$ : Employees working in manufacturing industries have impasse towards the development of proper policies at the organizational level for effectual implementation of QT\&T. Policies and accomplishment plan should be appropriately communicated to all the employees working in that organization.

7. Lack of proper training and education $\left(\mathbf{B}_{7}\right)$ : Newall and Dale (1990), Ljungström and Klefsjö (2002) and Talib et al., (2011) reveal that deprived learning acts as a key barrier in the growth and completion of quality program. Improper training and education leads to failure while utilizing QT\&T in manufacturing organizations. Thus, training programs are effectively intended and correctly implemented

8. Lack top Management Support $\left(\mathbf{B}_{8}\right)$ : Top management should bring continual support for proper utilization of QT\&T in manufacturing organizations. Lack of top-management commitment empowers lack of experience, training, resistance to change, and hesitation in initiating development programs. It also tackles with acquaintance arrangement and support system that facilitates sharing and request of knowledge (Huang \& Lin, 2010).

9. Divergence with other quality management system (B9): The quality systems like PokaYoke, Six Sigma and ISO 9000 varies in terms of requirements from different departments to different organizations (Liker \& Hoseus, 2008). This disparity in the requirements of quality systems overwhelms to choose program for completion and engage their employees in improvement activities.

10. Deficient planning and implementation $\left(\mathbf{B}_{10}\right)$ : The lack of strategic planning leads to unproductive improvement in quality. This is leading barrier while implementation quality enhancement programs in Indian manufacturing organizations (Warwood \& Knowles, 2004; Kumar et al., 2007). It also shares rise in knowledge for flow utilization (Wu 2008).

11. Accessibility of time and space $\left(\mathbf{B}_{11}\right)$ : Manufacturing organizations requires time and space for face-to-face communication and the amalgamation of knowledge (Herrgard 2000; Cheng et al., 2008). This is the critical barrier which hinders the worker to generate their cooperative relationship with others by the convenience of time and space.

12. Keen to share knowledge $\left(\mathbf{B}_{12}\right)$ : There should be an appropriate loom to convey knowledge within and outside the manufacturing organizations. Knowledge sharing defined as the synergistic process by which the employers and the employees getting advantage from renewed knowledge (Capó-Vicedo et al., 2011). Eagerness to contribute knowledge acts as an enabler of knowledge surge in the organization (Hence Kuo, 2013).

\section{Solution methodology}

\subsection{Questionnaire based survey}

After discussion with experts (industrial and academicians), the barriers influencing the utilization of QT\&T in manufacturing organizations have been validated by using questionnaire based survey. For this reason, a questionnaire was developed on 5 point Likart scale. Numeral 1 donates barrier with the least importance while numeral 5 represents barrier with the most importance. The questionnaires were 
directed to 270 manufacturing organization for knowing the impact of identified barriers for utilization of QT\&T. Out of those 270 questionnaires, only 102 completely filled questionnaires were received and were used for further analysis. Survey suggested that no new barrier was found in the study. The data of the responding organizations is given in Table 1.

Table 1

Data of responding organizations

\begin{tabular}{|c|c|c|c|c|}
\hline Sr no & Description of data & Range & No. of organizations & Percentage (\%) \\
\hline \multirow[t]{6}{*}{1} & Type of organization & Automobile & 30 & 29.41 \\
\hline & & Refrigeration & 20 & 19.60 \\
\hline & & Electrical & 13 & 12.74 \\
\hline & & Sheet metal & 18 & 17.64 \\
\hline & & Others & 21 & 20.58 \\
\hline & & Total organizations & 102 & $99.97 *$ \\
\hline \multirow[t]{6}{*}{2} & Number of employees & Less than 100 & 18 & 17.64 \\
\hline & & $100-250$ & 15 & 14.70 \\
\hline & & $251-500$ & 28 & 27.45 \\
\hline & & $501-1000$ & 21 & 20.58 \\
\hline & & 1001 and above & 20 & 19.60 \\
\hline & & Total employees & 102 & $99.97 *$ \\
\hline \multirow[t]{6}{*}{3} & Turnover (in Rs crores) & Less than 50 & 17 & 16.66 \\
\hline & & $51-100$ & 23 & 22.54 \\
\hline & & $101-150$ & 26 & 25.49 \\
\hline & & $151-200$ & 21 & 20.58 \\
\hline & & More than 200 & 15 & 14.70 \\
\hline & & Total Turnover & 102 & $99.97 *$ \\
\hline \multirow[t]{6}{*}{4} & Department & Quality & 29 & 28.43 \\
\hline & & Production & 23 & 22.54 \\
\hline & & Marketing & 19 & 18.62 \\
\hline & & PPC & 17 & 16.66 \\
\hline & & Others & 14 & 13.72 \\
\hline & & Total Departments & 102 & $99.97 *$ \\
\hline
\end{tabular}

*Considering only two digits fractional decimals

The survey data of respondent's was statically analyzed by using SPSS software. Result statistics of survey data is shown in Table 2.

Table 2

Statistics of QT\&T barriers

\begin{tabular}{ccccccccccccc}
\hline & $\mathrm{B}_{1}$ & $\mathrm{~B}_{2}$ & $\mathrm{~B}_{3}$ & $\mathrm{~B}_{4}$ & $\mathrm{~B}_{5}$ & $\mathrm{~B}_{6}$ & $\mathrm{~B}_{7}$ & $\mathrm{~B}_{8}$ & $\mathrm{~B}_{9}$ & $\mathrm{~B}_{10}$ & $\mathrm{~B}_{11}$ & $\mathrm{~B}_{12}$ \\
\hline Mean & 1.87 & 1.97 & 1.96 & 2.14 & 2.39 & 2.16 & 2.47 & 2.36 & 2.57 & 2.59 & 2.61 & 2.26 \\
Median & 2.00 & 2.00 & 2.00 & 2.00 & 2.00 & 1.00 & 2.00 & 2.00 & 2.00 & 2.00 & 2.00 & 1.00 \\
Mode & 2 & 2 & 2 & 2 & 1 & 1 & 1 & 1 & 1 & 1 & 1 & 1 \\
Std. Deviation & .804 & .710 & .878 & 1.135 & 1.470 & 1.447 & 1.527 & 1.553 & 1.479 & 1.451 & 1.470 & 1.567 \\
Variance & .647 & .504 & .771 & 1.288 & 2.162 & 2.094 & 2.331 & 2.412 & 2.188 & 2.106 & 2.162 & 2.454 \\
Range & 3 & 3 & 4 & 4 & 4 & 4 & 4 & 4 & 4 & 4 & 4 & 4 \\
\hline
\end{tabular}

Table 3

Correlation Coefficients for QT\&T barriers

\begin{tabular}{ccccccccccccc}
\hline & $\mathrm{b} 1$ & $\mathrm{~b} 2$ & $\mathrm{~b} 3$ & $\mathrm{~b} 4$ & $\mathrm{~b} 5$ & $\mathrm{~b} 6$ & $\mathrm{~b} 7$ & $\mathrm{~b} 8$ & $\mathrm{~b} 9$ & $\mathrm{~b} 10$ & $\mathrm{~b} 11$ & $\mathrm{~b} 12$ \\
\hline $\mathrm{b} 1$ & 1.000 & $.603^{* *}$ & $.421^{* *}$ & -.029 & $.265^{* *}$ & .078 & .024 & -.067 & .103 & -.133 & -.049 & -.033 \\
b2 & $.603^{* *}$ & 1.000 & $.599^{* *}$ & .177 & $.348^{* *}$ & .080 & -.052 & .015 & .063 & -.067 & .090 & .116 \\
$\mathrm{~b} 3$ & $.421^{* *}$ & $.599^{* *}$ & 1.000 & $.500^{* *}$ & .169 & -.089 & .003 & .054 & -.107 & -.143 & -.046 & -.151 \\
$\mathrm{~b} 4$ & -.029 & .177 & $.500^{* *}$ & 1.000 & $.438^{* *}$ & .035 & -.104 & -.092 & $-.205^{*}$ & .003 & .030 & .032 \\
$\mathrm{~b} 5$ & $.265^{* *}$ & $.348^{* *}$ & .169 & $.438^{* *}$ & 1.000 & $.648^{* *}$ & $.262^{* *}$ & .025 & -.065 & -.113 & -.132 & $-.204^{*}$ \\
b6 & .078 & .080 & -.089 & .035 & $.648^{* *}$ & 1.000 & $.562^{* *}$ & $.252^{*}$ & -.047 & -.184 & $-.214^{*}$ & $-.216^{*}$ \\
b7 & .024 & -.052 & .003 & -.104 & $.262^{* *}$ & $.562^{* *}$ & 1.000 & $.527^{* *}$ & .128 & $-.233^{*}$ & $-.206^{*}$ & $-.354^{* *}$ \\
b8 & -.067 & .015 & .054 & -.092 & .025 & $.252^{*}$ & $.527^{* *}$ & 1.000 & $.555^{* *}$ & .088 & .145 & -.110 \\
b9 & .103 & .063 & -.107 & $-.205^{*}$ & -.065 & -.047 & .128 & $.555^{* *}$ & 1.000 & $.530^{* *}$ & $.407^{* *}$ & .178 \\
b10 & -.133 & -.067 & -.143 & .003 & -.113 & -.184 & $-.233^{*}$ & .088 & $.530^{* *}$ & 1.000 & $.868^{* *}$ & $.671^{* *}$ \\
b11 & -.049 & .090 & -.046 & .030 & -.132 & $-.214^{*}$ & $-.206^{*}$ & .145 & $.407^{* *}$ & $.868^{* *}$ & 1.000 & $.764^{* *}$ \\
b12 & -.033 & .116 & -.151 & .032 & $-.204^{*}$ & $-.216^{*}$ & $-.354^{* *}$ & -.110 & .178 & $.671^{* *}$ & $.764^{* *}$ & 1.000 \\
\hline **Correlation is significant at the 0.01 level (2-tailed). & & & & & & & & \\
*Correlation is significant at the 0.05 level (2-tailed). & & & & & & & &
\end{tabular}


Afterwards, Spearman's rho Correlation Coefficient test among the barriers of QT\&T is conducted to check the existence of any multi-co linearity occurrence. Table 3 donates the correlation coefficients between barriers of QT\&T and signifies no occurrence of multi- co linearity.

\subsection{ISM methodology}

Interpretive structural modelling (ISM) is a decision making tool that can identify various variables categorizing a problem (Warfield, 1974; Sage, 1977). It includes structured approach of set of variables or barriers identifying relationships among specific items which define a problem or an issue (Jharkharia \& Shankar, 2004). In other words, it gives planned and well defined summary of framework for challenging issues and thoughts for researchers to get obvious picture of the system. The challenge of recent scenario is to assemble the barriers affecting the utilization of QT\&T in manufacturing organizations. Manufacturing organizations use to understand and implement QT\&T in most effective manner in accordance to their applications and usages. Therefore, it becomes necessary to practice a hierarchy model to recognize certain barriers for effective utilization of QT\&T. ISM approach is helpful for determining complex relationships among the various barriers involved in manufacturing organizations. Also ISM methodology helps the decision makers to find out the order and magnitude by identifying the relationships among the elements (Yin et al., 2012; Govindan et al., 2015). Many researchers have used blend of ISM and MICMAC approach in different areas such as operational management, logistics and scheduling for systematic structured analysis (SSA). Table 4 shows the recent applications of ISMMICMAC approach as reported in literature.

\section{Table 4}

Recent applications of ISM approach

\begin{tabular}{ll}
\hline Authors (years) & Focus area of combined ISM and MICMAC approach \\
\hline Ertas et al. (2016) & Complexity of system maintainability analysis \\
Vasanthakumar et al.(2016) & Analysis of factors influencing lean remanufacturing practices \\
Purohit et al .(2016) & Framework for mass customization enablers \\
Dwivedi et al .(2016) & Driving innovation through big open linked data (BOLD) \\
Shen et al .(2016) & Implementation of Emission Trading System in the Chinese building sector \\
Trivedi et al .(2015) & Analysis of key factors for waste management in humanitarian response \\
Luthra et al .(2015) & $\begin{array}{l}\text { Analysis of interactions among critical success factors to implement green supply chain management } \\
\text { towards sustainability }\end{array}$ \\
\hline Venkatesh et al .(2015) & Analysis on supply chain risks in Indian apparel retail chains and proposal of risk prioritization model \\
Garg et al .(2015) & Barriers to implementation of IT in educational institutions \\
Rajaprasad et al .(2015) & Factors Influencing Implementation of OHSAS 18001 in Indian Construction Organizations \\
Attri and Grover (2015a) & Analyzing the scheduling system stage of PSLC \\
Attri and Grover (2015b) & Contextual relationship among the QEFs of inventory control system stage \\
\hline
\end{tabular}

Some important benefits of ISM methodology are:

- Identifies different variables related to an issue.

- Identify relationships between factors by plotting a digraph model.

- Involves both group and individual learning by complex problem-solving practice.

- Examine different variables involved in complex problem in terms of order and direction.

The process sequence for development of ISM model is shown in Fig. 1. Various steps involved in ISM methodology (Kannan et al., 2009; Vinodh et al., 2016) are as follows,

1. Analyze the literature and get experts' opinions to identify the various barriers affecting the utilization of QT\&T in manufacturing organizations by group problem-solving method or by survey;

2. Among the identified barriers, develop contextual relationships;

3. Build up a structural self-interaction matrix (SSIM) of elements. This matrix indicates the pair wise relationship among barriers considered for analysis;

4. Develop initial and final reachability matrix from SSIM and check it for transitivity;

5. Partition final reachability matrix into different levels and convert into lower triangular matrix (conical matrix); 
6. Build the ISM-based directed graph (digraph) on the basis of relationships given in final reachability matrix after the removal of transitive links;

7. Perform MICMAC analysis after converting digraph into an ISM model;

8. Review the ISM model for theoretical inconsistency, and carry out necessary modifications, if required.

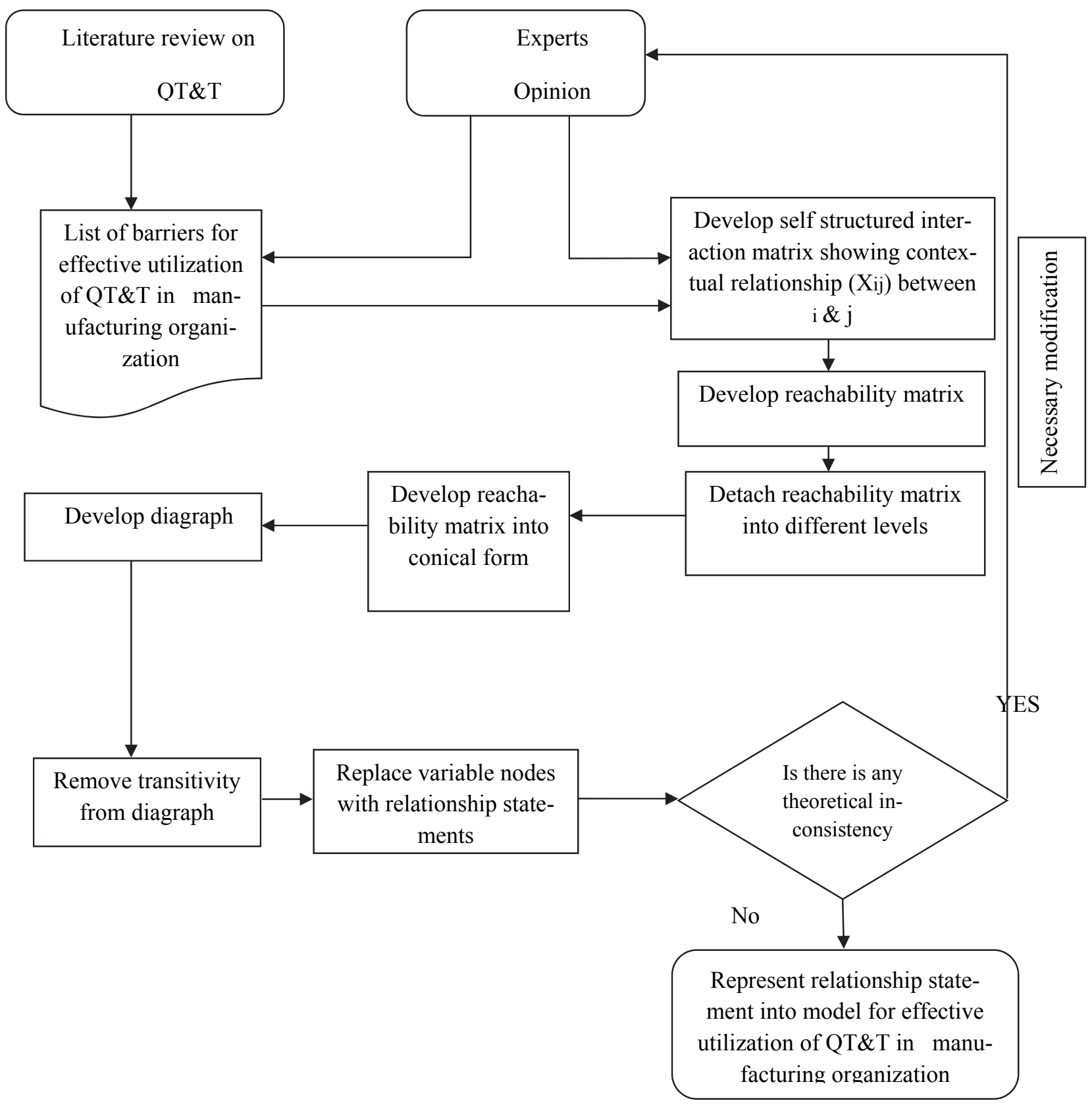

Fig. 1. Process sequence of ISM model (adapted from Govindan et al., 2012)

\subsubsection{Build up structural self-interaction matrix (SSIM)}

In order to explore the barriers affecting utilization of QT\&T, a contextual relationship of "give rise to" was used in this paper. The expert panel was utilized for pair-wise comparisons to identify the contextual relationship among the barriers. Following four symbols have been used for describing relationship between the barriers $i$ and $j$. 
- $\quad \mathrm{V}$ - when barrier $i$ will give rise to barrier $j$;

- A- when barrier $j$ will give rise to barrier $i$;

- $\quad \mathrm{X}$-when barriers $i$ and $j$ will give rise to each other;

- O-when barriers $i$ and $j$ have no relationship;

On the basis of contextual relationship among different barriers, SSIM has been obtained as shown in Table 5 .

Table 5

Structural self-interactive matrix (SSIM)

\begin{tabular}{llllllllllll}
\hline Barriers with codes & $\mathrm{B}_{12}$ & $\mathrm{~B}_{11}$ & $\mathrm{~B}_{10}$ & $\mathrm{~B}_{9}$ & $\mathrm{~B}_{8}$ & $\mathrm{~B}_{7}$ & $\mathrm{~B}_{6}$ & $\mathrm{~B}_{5}$ & $\mathrm{~B}_{4}$ & $\mathrm{~B}_{3}$ & $\mathrm{~B}_{2}$ \\
\hline Employee's resistance to change $\left(\mathrm{B}_{1}\right)$ & $\mathrm{O}$ & $\mathrm{O}$ & $\mathrm{A}$ & $\mathrm{O}$ & $\mathrm{A}$ & $\mathrm{A}$ & $\mathrm{A}$ & $\mathrm{V}$ & $\mathrm{V}$ & $\mathrm{A}$ & $\mathrm{A}$ \\
Motivational technique and Recipient organizations $\left(\mathrm{B}_{2}\right)$ & $\mathrm{O}$ & $\mathrm{O}$ & $\mathrm{A}$ & $\mathrm{O}$ & $\mathrm{A}$ & $\mathrm{A}$ & $\mathrm{A}$ & $\mathrm{V}$ & $\mathrm{V}$ & $\mathrm{O}$ & \\
Lack of continuous communication $\left(\mathrm{B}_{3}\right)$ & $\mathrm{X}$ & $\mathrm{A}$ & $\mathrm{A}$ & $\mathrm{V}$ & $\mathrm{A}$ & $\mathrm{A}$ & $\mathrm{A}$ & $\mathrm{V}$ & $\mathrm{V}$ & & \\
Inability to change organizational Culture $\left(\mathrm{B}_{4}\right)$ & $\mathrm{O}$ & $\mathrm{O}$ & $\mathrm{A}$ & $\mathrm{O}$ & $\mathrm{A}$ & $\mathrm{A}$ & $\mathrm{A}$ & $\mathrm{A}$ & & & \\
Inadequate coordination and teamwork $\left(\mathrm{B}_{5}\right)$ & $\mathrm{O}$ & $\mathrm{O}$ & $\mathrm{A}$ & $\mathrm{O}$ & $\mathrm{A}$ & $\mathrm{A}$ & $\mathrm{A}$ & & & \\
Dilemma about organization policies $\left(\mathrm{B}_{6}\right)$ & $\mathrm{A}$ & $\mathrm{A}$ & $\mathrm{A}$ & $\mathrm{V}$ & $\mathrm{A}$ & $\mathrm{V}$ & & & \\
Lack of proper training and education $\left(\mathrm{B}_{7}\right)$ & $\mathrm{O}$ & $\mathrm{A}$ & $\mathrm{A}$ & $\mathrm{O}$ & $\mathrm{A}$ & & & & \\
Lack top Management Support $\left(\mathrm{B}_{8}\right)$ & $\mathrm{O}$ & $\mathrm{A}$ & $\mathrm{V}$ & $\mathrm{V}$ & & & & & \\
Divergence with other quality management system $\left(\mathrm{B}_{9}\right)$ & $\mathrm{O}$ & $\mathrm{A}$ & $\mathrm{A}$ & & & & & & \\
Deficient planning and implementation $\left(\mathrm{B}_{10}\right)$ & $\mathrm{O}$ & $\mathrm{A}$ & & & & & & & \\
Accessibility of time and space $\left(\mathrm{B}_{11}\right)$ & $\mathrm{O}$ & & & & & & & & & &
\end{tabular}

\subsubsection{Development of initial and final Reachability matrix}

ISM methodology transforms the symbols $\mathrm{V}, \mathrm{A}, \mathrm{X}, \mathrm{O}$ into binary numbers i.e. ' 0 ' and. ' 1 ' (known as initial reachability matrix) as illustrate in table VI. Following are the rules employed for creation of initial reachability matrix:

- The existence of $\mathrm{V}$ in SSIM reveals to apply ' 1 ' in $(i, j)$ entry and ' 0 ' in the $(j, i)$ entry in the reachability matrix.

- The existence of A in SSIM reveals to apply ' 0 ' in $(i, j)$ entry and ' 1 ' in the $(j, i)$ entry in the reachability matrix.

- The existence of X in SSIM reveals to apply ' 1 ' in both $(i, j)$ and $(j, i)$ entries in the reachability matrix.

- The existence of O in SSIM reveals to apply ' 0 ' in both $(i, j)$ and $(j, i)$ entries in the reachability matrix.

On the basis above mentioned rules, initial reachability matrix is accomplished as stated in Table 6 .

Table 6

Initial reachability matrix

\begin{tabular}{|c|c|c|c|c|c|c|c|c|c|c|c|c|}
\hline Barriers & $\mathrm{B}_{1}$ & $\mathrm{~B}_{2}$ & $\mathrm{~B}_{3}$ & $\mathrm{~B}_{4}$ & $\mathrm{~B}_{5}$ & $\mathrm{~B}_{6}$ & $\mathrm{~B}_{7}$ & $\mathrm{~B}_{8}$ & $\mathrm{~B}_{9}$ & $\mathrm{~B}_{10}$ & $\mathrm{~B}_{11}$ & $\mathrm{~B}_{12}$ \\
\hline $\mathrm{B}_{1}$ & 1 & 0 & 0 & 1 & 1 & 0 & 0 & 0 & 0 & 0 & 0 & 0 \\
\hline $\mathrm{B}_{2}$ & 1 & 1 & 0 & 1 & 1 & 0 & 0 & 0 & 0 & 0 & 0 & 0 \\
\hline $\mathrm{B}_{3}$ & 1 & 0 & 1 & 1 & 1 & 0 & 0 & 0 & 1 & 0 & 0 & 1 \\
\hline $\mathrm{B}_{4}$ & 0 & 0 & 0 & 1 & 0 & 0 & 0 & 0 & 0 & 0 & 0 & 0 \\
\hline $\mathrm{B}_{5}$ & 0 & 0 & 0 & 1 & 1 & 0 & 0 & 0 & 0 & 0 & 0 & 0 \\
\hline $\mathrm{B}_{6}$ & 1 & 1 & 1 & 1 & 1 & 1 & 1 & 0 & 1 & 0 & 0 & 0 \\
\hline $\mathrm{B}_{7}$ & 1 & 1 & 1 & 1 & 1 & 0 & 1 & 0 & 0 & 0 & 0 & 0 \\
\hline $\mathrm{B}_{8}$ & 1 & 1 & 1 & 1 & 1 & 1 & 1 & 1 & 1 & 1 & 0 & 0 \\
\hline $\mathrm{B}_{9}$ & 0 & 0 & 0 & 0 & 0 & 0 & 0 & 0 & 1 & 0 & 0 & 0 \\
\hline $\mathrm{B}_{10}$ & 1 & 1 & 1 & 1 & 1 & 1 & 1 & 0 & 1 & 1 & 0 & 0 \\
\hline $\mathrm{B}_{11}$ & 0 & 0 & 1 & 0 & 0 & 1 & 1 & 1 & 1 & 1 & 1 & 0 \\
\hline $\mathrm{B}_{12}$ & 0 & 0 & 1 & 0 & 0 & 1 & 0 & 0 & 0 & 0 & 0 & 1 \\
\hline
\end{tabular}

After the development of initial reachability matrix (Table 7), final reachability matrix is obtained by the prologue of transitivity concept (as specify in step of ISM methodology) in the initial reachability 
matrix. Besides, it represents the indirect relationship between the barriers which clarifies that if barrier $i$ gives rise to barrier $j$ and barrier $j$ gives rise to barrier $k$, then barrier $i$ also gives rise to barrier $\mathrm{k}$.

Table 7

Final reachability matrix

\begin{tabular}{|c|c|c|c|c|c|c|c|c|c|c|c|c|c|}
\hline Barriers & $\mathrm{B}_{1}$ & $\mathrm{~B}_{2}$ & $\mathrm{~B}_{3}$ & $\mathrm{~B}_{4}$ & $\mathrm{~B}_{5}$ & $\mathrm{~B}_{6}$ & $\mathrm{~B}_{7}$ & $\mathrm{~B}_{8}$ & $\mathrm{~B}_{9}$ & $\mathrm{~B}_{10}$ & $\mathrm{~B}_{11}$ & $\mathrm{~B}_{12}$ & Driving power \\
\hline $\mathrm{B}_{1}$ & 1 & 0 & 0 & 1 & 1 & 0 & 0 & 0 & 0 & 0 & 0 & 0 & 3 \\
\hline $\mathrm{B}_{2}$ & 1 & 1 & 0 & 1 & 1 & 0 & 0 & 0 & 0 & 0 & 0 & 0 & 4 \\
\hline $\mathrm{B}_{3}$ & 1 & 0 & 1 & 1 & 1 & $1 *$ & 0 & 0 & 1 & 0 & 0 & 1 & 7 \\
\hline $\mathrm{B}_{4}$ & 0 & 0 & 0 & 1 & 0 & 0 & 0 & 0 & 0 & 0 & 0 & 0 & 1 \\
\hline $\mathrm{B}_{5}$ & 0 & 0 & 0 & 1 & 1 & 0 & 0 & 0 & 0 & 0 & 0 & 0 & 2 \\
\hline $\mathrm{B}_{6}$ & 1 & 1 & 1 & 1 & 1 & 1 & 1 & 0 & 1 & 0 & 0 & $1^{*}$ & 9 \\
\hline $\mathrm{B}_{7}$ & 1 & 1 & 1 & 1 & 1 & 0 & 1 & 0 & $1^{*}$ & 0 & 0 & $1^{*}$ & 8 \\
\hline $\mathrm{B}_{8}$ & 1 & 1 & 1 & 1 & 1 & 1 & 1 & 1 & 1 & 1 & 0 & $1 *$ & 11 \\
\hline $\mathrm{B}_{9}$ & 0 & 0 & 0 & 0 & 0 & 0 & 0 & 0 & 1 & 0 & 0 & 0 & 1 \\
\hline $\mathrm{B}_{10}$ & 1 & 1 & 1 & 1 & 1 & 1 & 1 & 0 & 1 & 1 & 0 & 0 & 10 \\
\hline $\mathrm{B}_{11}$ & $1^{*}$ & $1^{*}$ & 1 & $1 *$ & $1^{*}$ & 1 & 1 & 1 & 1 & 1 & 1 & 0 & 12 \\
\hline $\mathrm{B}_{12}$ & $1 *$ & $1 *$ & 1 & $1 *$ & $1 *$ & 1 & $1 *$ & 0 & $1 *$ & 0 & 0 & 1 & 9 \\
\hline $\begin{array}{l}\text { Dependence } \\
\text { Power }\end{array}$ & 9 & 7 & 7 & 11 & 10 & 6 & 6 & 2 & 8 & 3 & 1 & 7 & $77 / 77$ \\
\hline
\end{tabular}

\subsubsection{Levels partitioning}

Level partitioning enforce to disclose the levels of the barriers and to detach the barriers according to their levels. Reachability set contains the barrier itself and all the barriers which are driven by it but antecedent set contains the barrier itself and all the other barriers which drive it. The unlike sets of intersection and antecedent for all the barriers are obtained by partitioned final reachability matrix. In ISM methodology, level 1 is assigned to the barrier which attains the same reachability and intersection sets and is situated at the top position of ISM model. The top-level barriers would not help to achieve any other barrier above their own level in the model. Once the top-level barriers are recognized, they are alienated out from the rest of the barriers list and then the same procedure is adopted to find out the next level of barriers, and so on. These recognized levels help in building the directed graph as well as ISM model. Thakkar et al. (2005) suggested that factors and precedence relationships are carried out by level partitioning process in topological order. In the present work, partitioning of the final reachability matrix (for the recognition of level of barriers) in the current task is carried out by nine iterations stated in Table 10.

Table 10

Level partitions table

\begin{tabular}{|c|c|c|c|c|}
\hline Barriers $\left(\mathrm{B}_{i}\right)$ & $\begin{array}{c}\text { Reachability set } \\
\mathrm{R}\left(\mathrm{B}_{i}\right)\end{array}$ & $\begin{array}{l}\text { Antecedent set } \\
\mathrm{A}\left(\mathrm{B}_{i}\right)\end{array}$ & $\begin{array}{l}\text { Intersection set } \\
\mathrm{R}\left(\mathrm{B}_{i}\right) \cap \mathrm{A}\left(\mathrm{B}_{i}\right)\end{array}$ & Level \\
\hline $\mathrm{B}_{1}$ & $\mathrm{~B}_{1}$ & $\mathrm{~B}_{1,}, \mathrm{~B}_{2,}, \mathrm{~B}_{3,}, \mathrm{~B}_{6}, \mathrm{~B}_{7}, \mathrm{~B}_{8,} \mathrm{~B}_{10,}, \mathrm{~B}_{11}, \mathrm{~B}_{12}$ & $\mathrm{~B}_{1}$ & III \\
\hline $\mathrm{B}_{2}$ & $\mathrm{~B}_{2}$ & $\mathrm{~B}_{2,}, \mathrm{~B}_{6}, \mathrm{~B}_{7}, \mathrm{~B}_{8}, \mathrm{~B}_{10}, \mathrm{~B}_{11}, \mathrm{~B}_{12}$ & $\mathrm{~B}_{2}$ & IV \\
\hline $\mathrm{B}_{3}$ & $\mathrm{~B}_{3,}, \mathrm{~B}_{6}, \mathrm{~B}_{12}$ & $\mathrm{~B}_{3}, \mathrm{~B}_{6}, \mathrm{~B}_{7}, \mathrm{~B}_{8}, \mathrm{~B}_{10}, \mathrm{~B}_{11}, \mathrm{~B}_{12}$ & $\mathrm{~B}_{3,} \mathrm{~B}_{6}, \mathrm{~B}_{12}$ & IV \\
\hline $\mathrm{B}_{4}$ & $\mathrm{~B}_{4}$ & $\mathrm{~B}_{1,} \mathrm{~B}_{2,} \mathrm{~B}_{3}, \mathrm{~B}_{4}, \mathrm{~B}_{5}, \mathrm{~B}_{6}, \mathrm{~B}_{7}, \mathrm{~B}_{8}, \mathrm{~B}_{10}, \mathrm{~B}_{11}, \mathrm{~B}_{12}$ & $\mathrm{~B}_{4}$ & I \\
\hline $\mathrm{B}_{5}$ & $\mathrm{~B}_{5}$ & $\mathrm{~B}_{1}, \mathrm{~B}_{2,} \mathrm{~B}_{3}, \mathrm{~B}_{5}, \mathrm{~B}_{6}, \mathrm{~B}_{7}, \mathrm{~B}_{8}, \mathrm{~B}_{10}, \mathrm{~B}_{11} \mathrm{~B}_{12}$ & $\mathrm{~B}_{5}$ & II \\
\hline $\mathrm{B}_{6}$ & $\mathrm{~B}_{6}$ & $\mathrm{~B}_{6}, \mathrm{~B}_{8}, \mathrm{~B}_{10}, \mathrm{~B}_{11}$, & $\mathrm{B}_{6}$ & VI \\
\hline $\mathrm{B}_{7}$ & $\mathrm{~B}_{7}, \mathrm{~B}_{12}$ & $\mathrm{~B}_{6}, \mathrm{~B}_{7}, \mathrm{~B}_{8}, \mathrm{~B}_{10}, \mathrm{~B}_{11}, \mathrm{~B}_{12}$ & $\mathrm{~B}_{7}, \mathrm{~B}_{12}$ & $\mathrm{~V}$ \\
\hline $\mathrm{B}_{8}$ & $\mathrm{~B}_{8}$ & $\mathrm{~B}_{8}, \mathrm{~B}_{11}$ & $\mathrm{~B}_{8}$ & VIII \\
\hline $\mathrm{B}_{9}$ & $\mathrm{~B}_{9}$ & $\mathrm{~B}_{3}, \mathrm{~B}_{6} \mathrm{~B}_{7} \mathrm{~B}_{8} \mathrm{~B}_{9} \mathrm{~B}_{10} \mathrm{~B}_{11} \mathrm{~B}_{12}$ & $\mathrm{~B}_{9}$ & I \\
\hline $\mathrm{B}_{10}$ & $\mathrm{~B}_{10}$ & $\mathrm{~B}_{8}, \mathrm{~B}_{10}, \mathrm{~B}_{11}$ & $\mathrm{~B}_{10}$ & VII \\
\hline $\mathrm{B}_{11}$ & $\mathrm{~B}_{11}$ & $\mathrm{~B}_{11}$ & $\mathrm{~B}_{11}$ & IX \\
\hline $\mathrm{B}_{12}$ & $\mathrm{~B}_{6}, \mathrm{~B}_{7}, \mathrm{~B}_{12}$ & $\mathrm{~B}_{6}, \mathrm{~B}_{7}, \mathrm{~B}_{8}, \mathrm{~B}_{10}, \mathrm{~B}_{11}, \mathrm{~B}_{12}$ & $\mathrm{~B}_{6}, \mathrm{~B}_{7}, \mathrm{~B}_{12}$ & V \\
\hline
\end{tabular}

\subsubsection{Development of lower triangular matrix}

Afterwards, the barriers of same level across the rows and columns are clubbed together from the final reachability matrix in order to develop lower triangular matrix. This rearrangement of barriers into lower triangular form leads to the computation of both driver and dependence power for allocation of 
barriers according to their respective levels by calculating ranks. Driver power is obtained by adding up the number of $1 \mathrm{~s}$ in equivalent rows and dependence power is obtained by adding up the number of $1 \mathrm{~s}$ in equivalent columns. Table 9 shows the driver and dependence power of each barrier. It is concluded that barrier $\left(\mathrm{B}_{4}, \mathrm{~B}_{9}\right)$ with level I attains at the top position and barrier $\left(\mathrm{B}_{11}\right)$ with level 9 placed at the bottom and resulting the formation of structured model form digraph.

Table 9

Lower triangular matrix

\begin{tabular}{|c|c|c|c|c|c|c|c|c|c|c|c|c|c|c|}
\hline Barriers & $\mathrm{B}_{4}$ & $\mathrm{~B}_{9}$ & $\mathrm{~B}_{5}$ & $\mathrm{~B}_{1}$ & $\mathrm{~B}_{2}$ & $\mathrm{~B}_{3}$ & $\mathrm{~B}_{7}$ & $\mathrm{~B}_{12}$ & $\mathrm{~B}_{6}$ & $\mathrm{~B}_{10}$ & $\mathrm{~B}_{8}$ & $\mathrm{~B}_{11}$ & Driver power & Rank \\
\hline $\mathrm{B}_{4}$ & 1 & 0 & 0 & 0 & 0 & 0 & 0 & 0 & 0 & 0 & 0 & 0 & 1 & 10 \\
\hline $\mathrm{B}_{9}$ & 0 & 1 & 0 & 0 & 0 & 0 & 0 & 0 & 0 & 0 & 0 & 0 & 1 & 10 \\
\hline $\mathrm{B}_{5}$ & 1 & 0 & 1 & 0 & 0 & 0 & 0 & 0 & 0 & 0 & 0 & 0 & 2 & 9 \\
\hline $\mathrm{B}_{1}$ & 1 & 0 & 1 & 1 & 0 & 0 & 0 & 0 & 0 & 0 & 0 & 0 & 3 & 8 \\
\hline $\mathrm{B}_{2}$ & 1 & 0 & 1 & 1 & 1 & 0 & 0 & 0 & 0 & 0 & 0 & 0 & 4 & 7 \\
\hline $\mathrm{B}_{3}$ & 1 & 1 & 1 & 1 & 0 & 1 & 0 & 1 & 1 & 0 & 0 & 0 & 7 & 6 \\
\hline $\mathrm{B}_{7}$ & 1 & 1 & 1 & 1 & 1 & 1 & 1 & 1 & 0 & 0 & 0 & 0 & 8 & 5 \\
\hline $\mathrm{B}_{12}$ & 1 & 1 & 1 & 1 & 1 & 1 & 1 & 1 & 1 & 0 & 0 & 0 & 9 & 4 \\
\hline $\mathrm{B}_{6}$ & 1 & 1 & 1 & 1 & 1 & 1 & 1 & 1 & 1 & 0 & 0 & 0 & 9 & 4 \\
\hline $\mathrm{B}_{10}$ & 1 & 1 & 1 & 1 & 1 & 1 & 1 & 1 & 1 & 0 & 1 & 0 & 10 & 3 \\
\hline $\mathrm{B}_{8}$ & 1 & 1 & 1 & 1 & 1 & 1 & 1 & 1 & 1 & 1 & 1 & 0 & 11 & 2 \\
\hline $\mathrm{B}_{11}$ & 1 & 1 & 1 & 1 & 1 & 1 & 1 & 1 & 1 & 1 & 1 & 1 & 12 & 1 \\
\hline Dependence Power & 11 & 8 & 10 & 9 & 7 & 7 & 6 & 7 & 6 & 2 & 3 & 1 & & \\
\hline Rank & 1 & 4 & 2 & 3 & 5 & 5 & 6 & 5 & 6 & 8 & 7 & 9 & & \\
\hline
\end{tabular}

\subsubsection{Development of digraph and ISM-based model}

On the basis of lower triangular matrix (Table 9), initial digraph comprising of transitive or indirect links is constructed by nodes and line of edges.

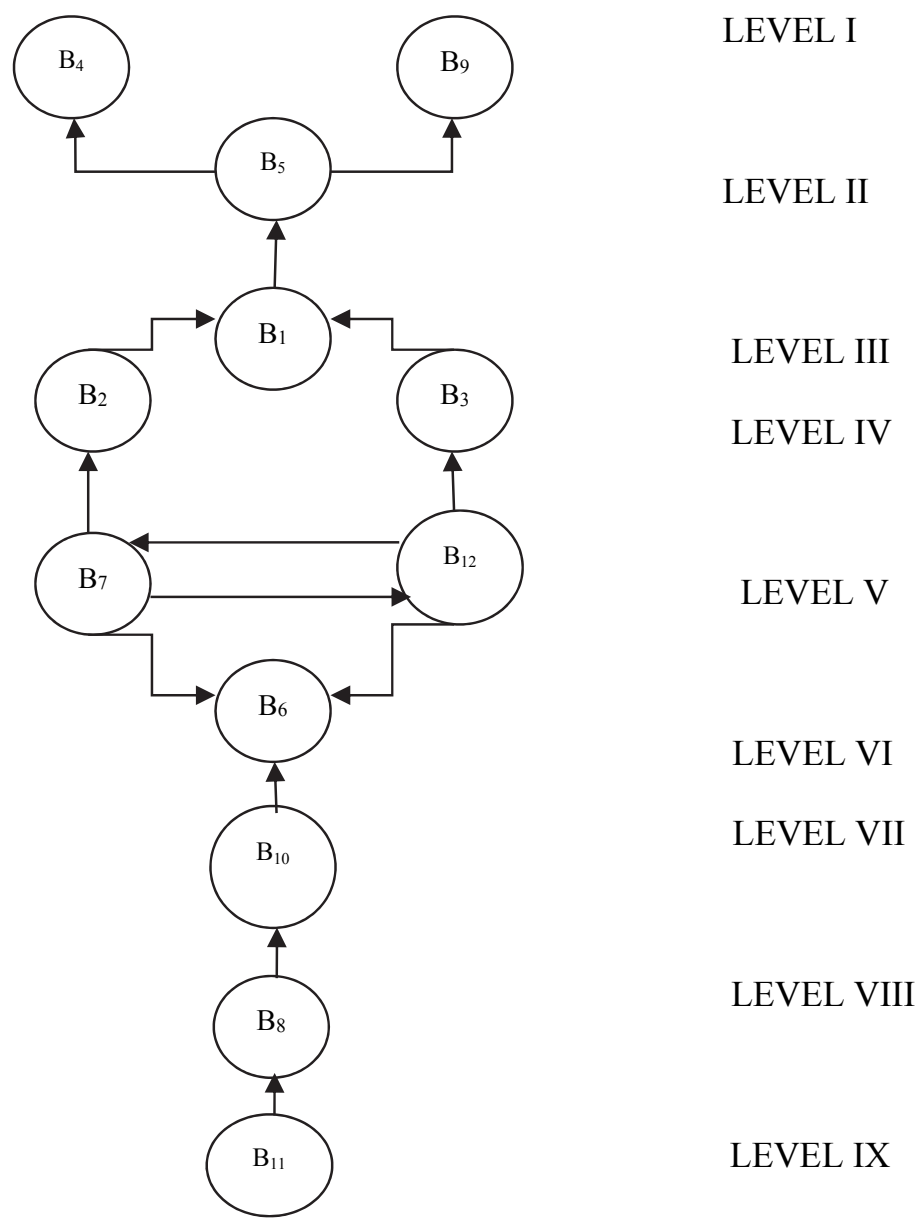

Fig. 2. Digraph of barriers affecting utilization of QT\&T in manufacturing organization 
Final diagraph (Fig. 2) is developed by eliminating the indirect links from initial digraph and is transformed into an ISM model (Fig. 3). This hierarchy model represents connection between the barriers along with their associated direction as illustrated below

\subsection{MICMAC analysis}

MICMAC is known as cross-impact matrix multiplication applied to classification derived from (Matriced'Impacts croises-multipication appliqué and clasment). It is based upon multiplication properties of matrices (Sharma et al., 1995). MICMAC analysis helps to analyze the barrier on the basis of their driver and dependence power and to group them accordingly (Singh et al., 2014). It starts with the calculation of both driver and dependence power for each barrier and categorizes the barrier into following four quadrants:

- Autonomous barriers (I $\mathbf{I}^{\text {st }}$ quadrant): These barriers lie in first quadrant and signify their presence with weak driver and dependence power. They are promptly detached with few links.

- Dependent barriers (II ${ }^{\text {nd }}$ quadrant): These barriers lie in second quadrant and have weak driver power but strong dependence power. They are significantly exaggerated by various barriers

- Linkage barriers (III ${ }^{\text {rd }}$ quadrant): These barriers lie in third quadrant and have strong driver power along with the strong dependence power. Being an important quadrant the action made by these variables will affects others and vice versa.

- Independent barriers (IV ${ }^{\text {th }}$ quadrant): These barriers lie in forth quadrant and have strong driver power but weak dependence power. They have greater driver power above several barriers.

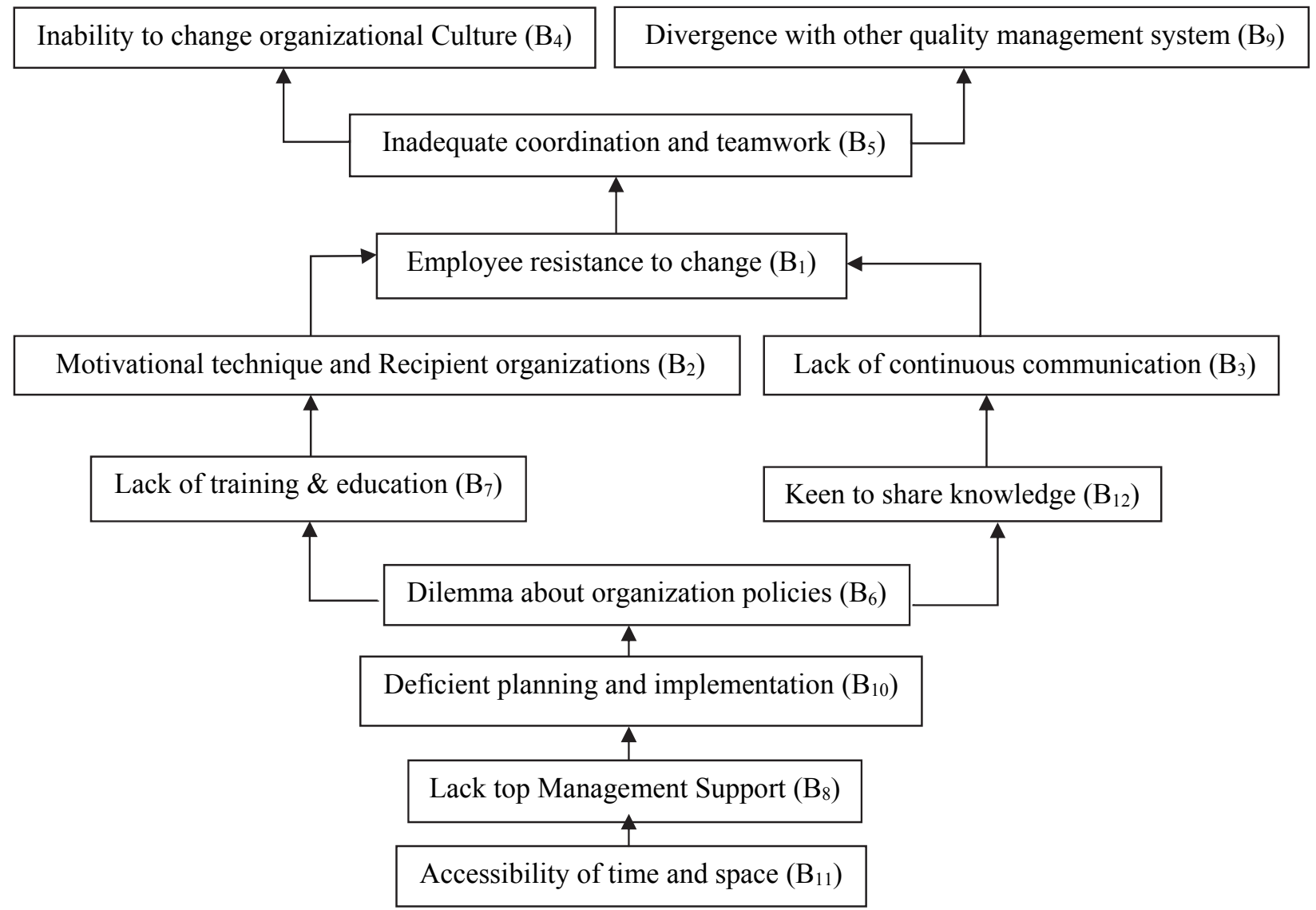

Fig. 3. Interpretive structural model showing levels of barriers affecting QT\&T 
The driver power \& dependence power diagram is constructed in Fig. 4. Abscissa represents dependence power and ordinate relates with driver power. The diagram so generated helps to conquer the classification of different barriers affecting the utilization of QT\&T in manufacturing organizations. This diagram is alienated into four quadrants. Bottom left contains autonomous barriers, bottom right consists of dependent barriers, top right and left quadrants comprises with linkage and Independent barriers collectively. From Fig. 4, it is concluded that there is no barrier under autonomous variable's quadrant. Two barriers drop under linkage variable's quadrant, five barriers beneath dependent quadrant and rest of it fall under independent barrier variable's quadrant. The driver and dependence power obtained through MICMAC analysis give visions about the relative significance and the interdependencies for effective utilization of QT\&T in manufacturing organizations and provide valuable understandings that can efficiently deploy these QT\&T for to persist effectiveness.

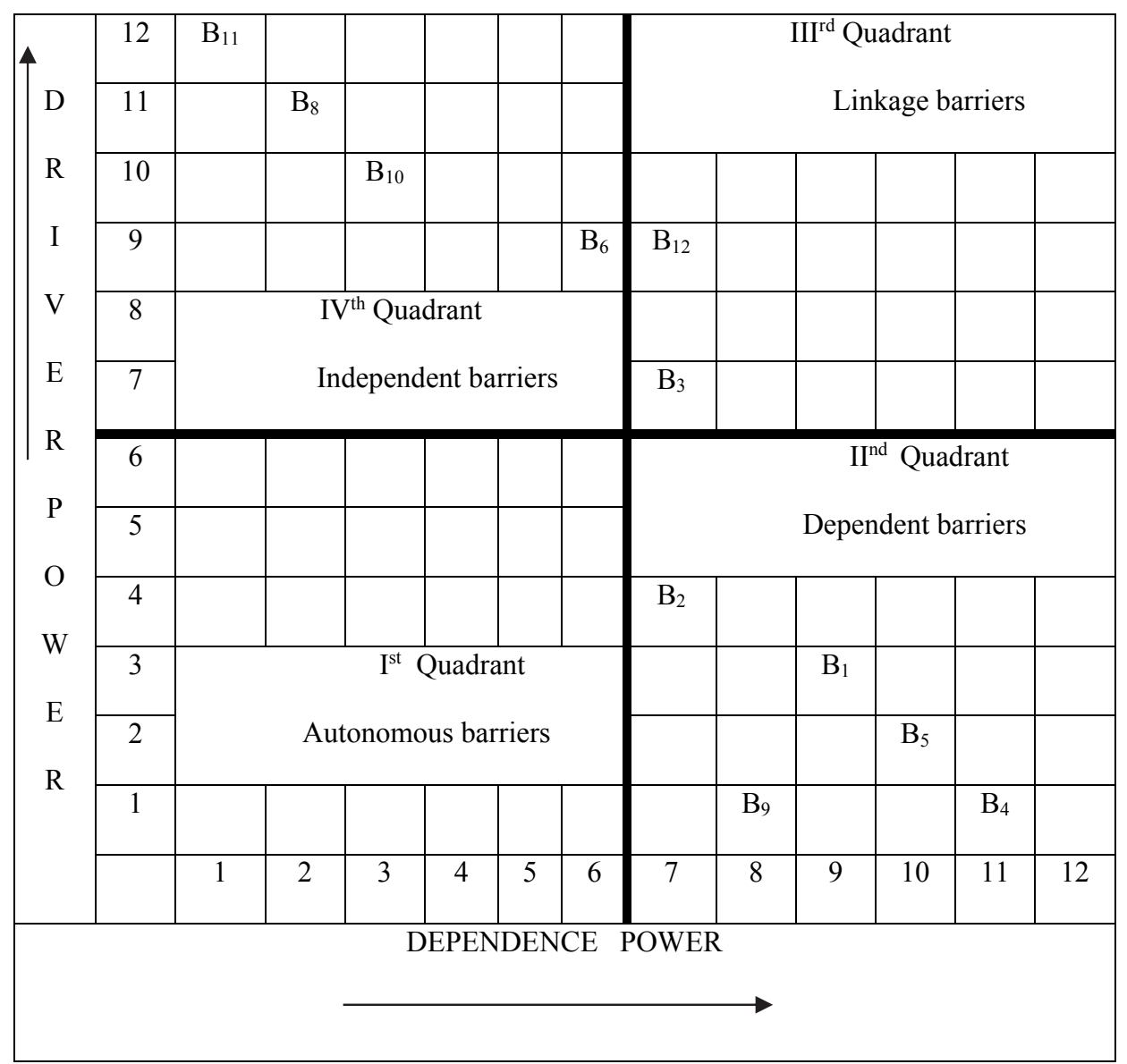

Fig. 4. Driver power-dependence graph

\section{Development of integrated model}

For perceived effectiveness, better and more refined approach has been used to upgrade the basic ISM model. Integrated model (Fig. 5) is the hierarchical order of barriers which is approximately analogous to that of conventional ISM model. An integrated model has been developed from MICMAC analysis by means of the driver and dependence powers of the barriers. Table 10 illustrates the calculation of effectiveness for each barrier by subtracting the dependence power from the driver power. The barriers having higher effectiveness are placed at the bottom and the barriers with lower effectiveness are placed at the top of the model on to other barriers. 
Table 10

Difference in driver power and dependency

\begin{tabular}{cccc}
\hline Barriers & Driver power & Dependence power & Effectiveness $=$ (driver power - dependence power) \\
\hline $\mathrm{B}_{1}$ & 3 & 9 & -6 \\
$\mathrm{~B}_{2}$ & 4 & 7 & -3 \\
$\mathrm{~B}_{3}$ & 7 & 7 & 0 \\
$\mathrm{~B}_{4}$ & 1 & 11 & -10 \\
$\mathrm{~B}_{5}$ & 2 & 10 & -8 \\
$\mathrm{~B}_{6}$ & 9 & 6 & 3 \\
$\mathrm{~B}_{7}$ & 6 & 8 & -2 \\
$\mathrm{~B}_{8}$ & 11 & 3 & 8 \\
$\mathrm{~B}_{9}$ & 1 & 8 & -7 \\
$\mathrm{~B}_{10}$ & 10 & 2 & 8 \\
$\mathrm{~B}_{11}$ & 1 & 12 & -11 \\
$\mathrm{~B}_{12}$ & 9 & 7 & 2 \\
\hline
\end{tabular}

An integrated model (Fig 5) implies to be more reliant and sophisticated for the representation of barriers affecting the utilization of QT\&T. After going through the integrated model, it is found that barrier $\left(\mathrm{B}_{11}\right)$ Accessibility of time and space, $\left(\mathrm{B}_{4}\right)$ Inability to change organizational Culture and $\left(\mathrm{B}_{5}\right)$ Inadequate coordination and teamwork are placed at the same bottom level of hierarchy and indicate independent barriers which drive the barriers situated at in higher level of the model.

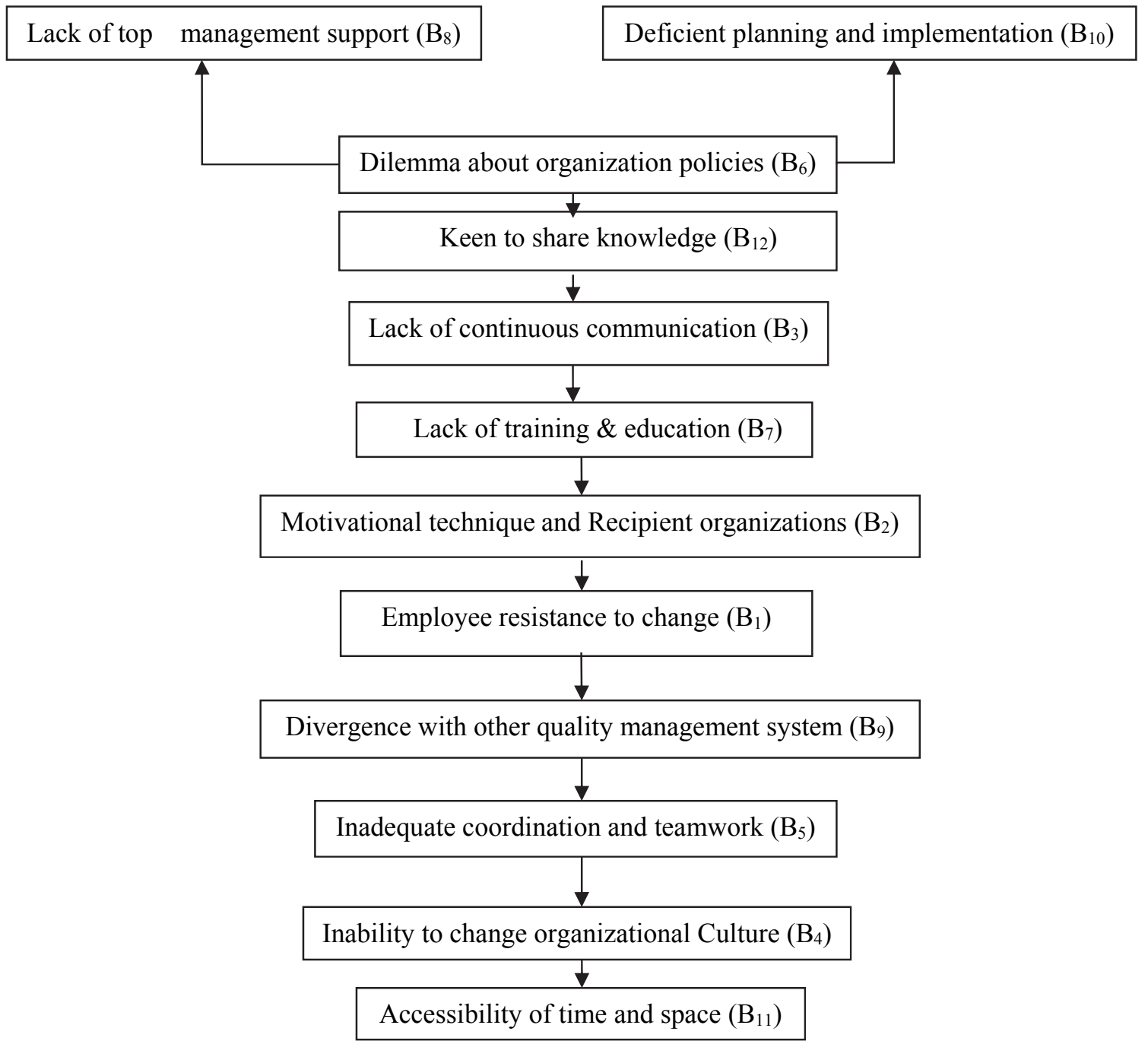

Fig. 5. Integrated model of barriers affecting manufacturing organization 
On the other hand, barriers specifically $\left(\mathrm{B}_{6}\right)$ Dilemma about organization policies, $\left(\mathrm{B}_{8}\right)$ lack of top management support and $\left(\mathrm{B}_{10}\right)$ Deficient planning and implementation have propensity to affect the manufacturing organization and appears at the top most position of the model and indicate dependent barriers which are driven by other barriers in the model.

\section{Discussion and conclusion}

The main objective of this paper was to analyze the barrier affecting the effective utilization of QT\&T in the manufacturing organizations. Twelve barriers have been identified from extensive literature analysis and experts opinions. Moreover, this research also endeavors to evaluate the effectiveness of different barriers inhibiting the proper execution of QT\&T in manufacturing organizations. In this paper, an integrated ISM model based on contextual relationships has been developed which identified barriers through methodical framework that evocates the picture and helps managers to productively employ the QT\&T in manufacturing organizations.

The basic ISM model allocates the known barriers into nine different levels which show the prolongation of inter-relationships among these measured barriers. With the help of ISM methodology, the model was developed. It has been observed that accessibility of time and space $\left(\mathrm{B}_{11}\right)$, lack of top management support $\left(\mathrm{B}_{8}\right)$ and deficient planning and implementation $\left(\mathrm{B}_{10}\right)$ situated at (IX,VIII\&VII) level of the ISM model. These are necessary inputs for any manufacturing organization to implement QT\&T with proper planning with the help of top management support incorporates with the accessibility of appropriate time and space. The level VI constitutes dilemma about organization policies $\left(\mathrm{B}_{6}\right)$ which brings inappropriate knowledge about manufacturing organization. Similarly, Lack of training \& education $\left(\mathrm{B}_{7}\right)$ and keen to share knowledge $\left(\mathrm{B}_{12}\right)$ both attains at same level of the hierarchy which substitute to integration of information with the aid of the incentive source. These barriers would lead to personalization of knowledge and further endorse integration of knowledge .Motivational technique and recipient organizations $\left(\mathrm{B}_{2}\right)$ with lack of continuous communication $\left(\mathrm{B}_{3}\right)$ together comprise at level IV which improves the mutual alliance and motivates well organizational culture. On the other hand, employee resistance to change $\left(\mathrm{B}_{1}\right)$ becomes dominant barrier while considering the efficient utilization of QT\&T in any manufacturing organizations and finally top level of ISM model contribute level II for Inadequate coordination and teamwork $\left(\mathrm{B}_{5}\right)$ which combines with inability to change organizational Culture $\left(\mathrm{B}_{4}\right)$ and divergence with other quality management system $\left(\mathrm{B}_{9}\right)$ together influence same level I and willing to deals with the effectiveness of manufacturing organization. All the nine levels will facilitate to enhanced effective coordination, effective utilization and proper utilization of QT\&T in manufacturing organization. The confirmation of ISM development with MICMAC analysis has been carried out with eleven experts (manufacturing organization practitioners - eight and academics three). The concluded ISM model was developed and MICMAC analysis is carried out which gives an evidence to show resemblance in interrelationships with different barriers associated to their driving power and dependence power. The second objective of present study is to carry out MICMAC analysis which defines barriers into four main quadrants (autonomous, linkage, dependent and independent) with their respective driver power and dependence. They are:

- Autonomous barriers: The driving-dependence power diagram (see Fig. 4) indicates that there are no autonomous barriers existing in this quadrant these barriers have weak driver and dependence power and thus donated by only few links which directly influence the system. None of the barriers exist in this quadrant.

- Dependent barriers: Dependent barriers are strongly dependent on other barriers. motivational technique and recipient organizations $\left(B_{2}\right)$, employee resistance to change $\left(B_{1}\right)$, inadequate coordination and teamwork $\left(\mathrm{B}_{5}\right)$, inability to change organizational culture $\left(\mathrm{B}_{4}\right)$ and divergence with other quality management system $\left(\mathrm{B}_{9}\right)$ have weak driving but have strong dependence power, and described as performance orientated (Figure 6).these barriers will appear at the top level of the ISM hierarchy and are therefore considered important barriers shown in Figure 3. 
- Linkages barriers: Linkage barriers are influenced by lower level barriers and in turn impact other barriers in the model, which may affect the successful knowledge flow in manufacturing organizations either in an optimistic or pessimistic way. Two barriers namely keen to share knowledge $\left(\mathrm{B}_{12}\right)$ and lack of continuous communication $\left(\mathrm{B}_{3}\right)$ fall under this quadrant. Managers have to take special care while handling such barriers.

- Independent barriers: Barriers like accessibility of time and space $\left(\mathrm{B}_{11}\right)$, lack of top management support $\left(\mathrm{B}_{8}\right)$, deficient planning and implementation $\left(\mathrm{B}_{10}\right)$, inadequate coordination and teamwork $\left(\mathrm{B}_{5}\right)$, lack of training \& education $\left(\mathrm{B}_{7}\right)$ are fall under this quadrant and are called independent barriers which drive other barriers and are subjected to be the most important barrier with high driver power than dependence power.

Afterward an Integrated ISM-MICMAC model has been developed shown in Figure 5. The analysis of Integrated ISM-MICMAC is as follows:

- Barriers like accessibility of time and space $\left(\mathrm{B}_{11}\right)$, Inability to change organizational Culture $\left(\mathrm{B}_{4}\right)$ and Inadequate coordination and teamwork $\left(\mathrm{B}_{5}\right)$ they all appear in the same level, i.e. at the bottom most level which means they drive the barriers present in top level of the model.

- Barriers namely keen to share knowledge $\left(\mathrm{B}_{12}\right)$, Lack of continuous communication $\left(\mathrm{B}_{3}\right)$, Lack of training \& education $\left(\mathrm{B}_{7}\right)$, Motivational technique and Recipient organizations $\left(\mathrm{B}_{2}\right)$, Employee resistance to change $\left(B_{1}\right)$ and Divergence with other quality management system $\left(B_{9}\right)$ fall under middle level which supports both top level and bottom most level of the hierarchy.

- Barriers specifically lack of top management support $\left(\mathrm{B}_{8}\right)$, deficient planning and implementation $\left(\mathrm{B}_{10}\right)$ and dilemma about organization policies $\left(\mathrm{B}_{6}\right)$ will retain at top most level and have propensity to refer decisions to higher levels in manufacturing organizations which implies that these are the dependent barriers and are driven by other barriers in the model.

The main limitations of present work is

- Validation of barriers is required by using structural equation modeling (SEM) approach or by performing the detailed case studies.

- Integrated ISM-MICMAC model has been developed through the input of experts and academicians and this lead to some biasness in the present research work.

The pragmatic research presented in this paper investigates the barriers that persuade the effectiveness of QT\&T. This research work developed an integrated ISM model that has not been statistically validated. So, in future, the developed model can be tested by structural modelling approach (SEM) that has the capability of test and validate this developed model. LISREL software can also be used to scrutinize the interactions derivative from the ISM model that has been recommended for Indian manufacturing organizations which assists to the novel work in field of QT\&T.

\section{References}

Abuelmaatti, A., \& Rezgui, Y. (2008). Virtual organizations in practice: a European perspective. AMCIS 2008 Proceedings, 142.

Attri, R., \& Grover, S. (2015a). Analyzing the scheduling system stage of production system life cycle. Management Science Letters, 5(5), 431-442.

Attri, R., \& Grover, S. (2015b). Contextual relationship among the quality enabled factors of inventory control system stage. International Journal of Recent advances in Mechanical Engineering, 4(2), 45-57.

Baumgartner, R. J., \& Zielowski, C. (2007). Analyzing zero emission strategies regarding impact on organizational culture and contribution to sustainable development. Journal of Cleaner Production, 15(13), 1321-1327. 
Capó-Vicedo, J., Mula, J., \& Capó, J. (2011). A social network-based organizational model for improving knowledge management in supply chains. Supply Chain Management: An International Journal, 16(4), 284-293.

Cheng, J. H., Yeh, C. H., \& Tu, C. W. (2008). Trust and knowledge sharing in green supply chains. Supply Chain Management: An International Journal, 13(4), 283-295.

Cohen, S., \& Brand, R. (1993). Total quality management in government. Jossey-Bass.

Dwivedi, Y. K., Janssen, M., Slade, E. L., Rana, N. P., Weerakkody, V., Millard, J., ... \& Snijders, D. (2017). Driving innovation through big open linked data (BOLD): Exploring antecedents using interpretive structural modelling. Information Systems Frontiers, 19(2), 197-212.

Ertas, A., Smith, M. W., Tate, D., Lawson, W. D., \& Baturalp, T. B. (2016). Complexity of system maintainability analysis based on the interpretive structural modeling methodology: Transdisciplinary approach. Journal of Systems Science and Systems Engineering, 25(2), 254-268.

Garg, A., Shukla, B., \& Kendall, G. (2015). Barriers to implementation of IT in educational institutions. The International Journal of Information and Learning Technology, 32(2), 94-108.

Gehin, A., Zwolinski, P., \& Brissaud, D. (2008). A tool to implement sustainable end-of-life strategies in the product development phase. Journal of Cleaner Production, 16(5), 566-576.

Govindan, K., Shankar, K. M., \& Kannan, D. (2016). Application of fuzzy analytic network process for barrier evaluation in automotive parts remanufacturing towards cleaner production-a study in an Indian scenario. Journal of Cleaner Production, 114, 199-213.

Govindan, K., Palaniappan, M., Zhu, Q., \& Kannan, D. (2012). Analysis of third party reverse logistics provider using interpretive structural modeling. International Journal of Production Economics, 140(1), 204-211.

Huang, C. C., \& Lin, S. H. (2010). Sharing knowledge in a supply chain using the semantic web. Expert Systems with Applications, 37(4), 3145-3161.

Ingwersen, W. W., \& Stevenson, M. J. (2012). Can we compare the environmental performance of this product to that one? An update on the development of product category rules and future challenges toward alignment. Journal of Cleaner Production, 24, 102-108.

Jharkharia, S., \& Shankar, R. (2004). IT enablement of supply chains: modeling the enablers. International Journal of Productivity and Performance Management, 53(8), 700-712.

Kaebernick, H., \& Kara, S. (2006, May). Environmentally sustainable manufacturing: a survey on industry practices. In Proceedings of 13th CIRP international conference on life cycle engineering (pp. 19-28).

Kannan, G., Pokharel, S., \& Kumar, P. S. (2009). A hybrid approach using ISM and fuzzy TOPSIS for the selection of reverse logistics provider. Resources, conservation and recycling, 54(1), 28-36.

Kara, S., Honke, I., \& Kaebernick, H. (2005, December). An integrated framework for implementing sustainable product development. In Environmentally Conscious Design and Inverse Manufacturing, 2005. Eco Design 2005. Fourth International Symposium on (pp. 684-691). IEEE.

Kara, S., Manmek, S., \& Kaebernick, H. (2007). An integrated methodology to estimate the external environmental costs of products. CIRP Annals-Manufacturing Technology, 56(1), 9-12.

Khurana, V.K. (2009). Management of Technology and Innovation. Ane Books Pvt Ltd.

Kuo, T. H. (2013). How expected benefit and trust influence knowledge sharing. Industrial Management \& Data Systems, 113(4), 506-522.

Liker, J. K., \& Hoseus, M. (2008). Toyota culture: The heart and soul of the Toyota way. McGrawHill, New York.

Ljungström, M., \& Klefsjö, B. (2002). Implementation obstacles for a work development-oriented TQM strategy. Total Quality Management, 13(5), 621-634.

Luthra, S., Garg, D., \& Haleem, A. (2015). An analysis of interactions among critical success factors to implement green supply chain management towards sustainability: An Indian perspective. Resources Policy, 46, 37-50.

Muhammad, N., \& Jeng Feng, C. (2014). Methodology to optimize value in discrete event imulation for production planning and control studies. In Proceedings of the International Conference on Industrial Engineering and Operations Management (pp. 676-684). 
Newall, D., \& Dale, B. G. (1991). The introduction and development of a quality improvement process: a study. The International Journal of Production Research, 29(9), 1747-1760.

Purohit, J. K., Mittal, M. L., Mittal, S., \& Sharma, M. K. (2016). Interpretive structural modeling-based framework for mass customisation enablers: An Indian footwear case. Production Planning \& Control, 27(9), 774-786.

Raj, T., \& Attri, R. (2011). Identification and modelling of barriers in the implementation of TQM. International Journal of Productivity and Quality Management, 8(2), 153-179.

Rajaprasad, S. V. S., \& Chalapathi, P. V. (2015). Factors influencing implementation of OHSAS 18001 in Indian construction organizations: interpretive structural modeling approach. Safety and health at work, 6(3), 200-205.

Sage, A. (1977). Interpretive structural modeling: methodology for large-scale systems, 91-164.

Sharma, H. D., \& Gupta, A. D. (1995). The objectives of waste management in India: a futures inquiry. Technological Forecasting and Social Change, 48(3), 285-309.

Shen, L., Song, X., Wu, Y., Liao, S., \& Zhang, X. (2016). Interpretive Structural Modeling based factor analysis on the implementation of Emission Trading System in the Chinese building sector. Journal of Cleaner Production, 127, 214-227.

Singh, J., Rastogi, V., \& Sharma, R. (2014). Implementation of 5S practices: A review. Uncertain Supply Chain Management, 2(3), 155-162.

Sureshchandar, G. S., Rajendran, C., \& Anantharaman, R. N. (2001). A holistic model for total quality service. International Journal of Service Industry Management, 12(4), 378-412.

Talib, F., Rahman, Z., \& Qureshi, M. N. (2011). Analysis of interaction among the barriers to total quality management implementation using interpretive structural modeling approach. Benchmarking: An International Journal, 18(4), 563-587.

Talib, F., Rahman, Z., \& Qureshi, M. N. (2011). An interpretive structural modelling approach for modelling the practices of total quality management in service sector. International Journal of Modelling in Operations Management, 1(3), 223-250.

Thakkar, J., Deshmukh, S. G., Gupta, A. D., \& Shankar, R. (2005, January). Selection of third-party logistics (3PL): a hybrid approach using interpretive structural modeling (ISM) and analytic network process (ANP). In Supply Chain Forum: An International Journal, 6(1), 32-46.

Trivedi, A., Singh, A., \& Chauhan, A. (2015). Analysis of key factors for waste management in humanitarian response: An interpretive structural modelling approach. International Journal of Disaster Risk Reduction, 14, 527-535.

Vasanthakumar, C., Vinodh, S., \& Ramesh, K. (2016). Application of interpretive structural modelling for analysis of factors influencing lean remanufacturing practices. International Journal of Production Research, 54(24), 7439-7452.

Venkatesh, V. G., Rathi, S., \& Patwa, S. (2015). Analysis on supply chain risks in Indian apparel retail chains and proposal of risk prioritization model using Interpretive structural modeling. Journal of Retailing and Consumer Services, 26, 153-167.

Vinodh, S., Ramesh, K., \& Arun, C. S. (2016). Application of interpretive structural modelling for analysing the factors influencing integrated lean sustainable system. Clean Technologies and Environmental Policy, 18(2), 413-428.

Warfield, J.N. (1974), Toward interpretation of complex structural modeling, IEEE Transaction on Systems and Man Cybernetics, 4(5), 405-417.

Yin, S. H., Wang, C. C., Teng, L. Y., \& Hsing, Y. M. (2012). Application of DEMATEL, ISM, and ANP for key success factor (KSF) complexity analysis in RD alliance. Scientific Research and Essays, 7(19), 1872-1890.

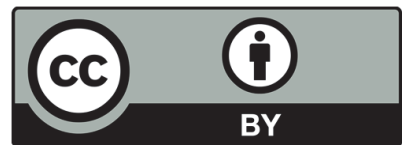

(C) 2017 by the authors; licensee Growing Science, Canada. This is an open access article distributed under the terms and conditions of the Creative Commons Attribution (CC-BY) license (http://creativecommons.org/licenses/by/4.0/). 